
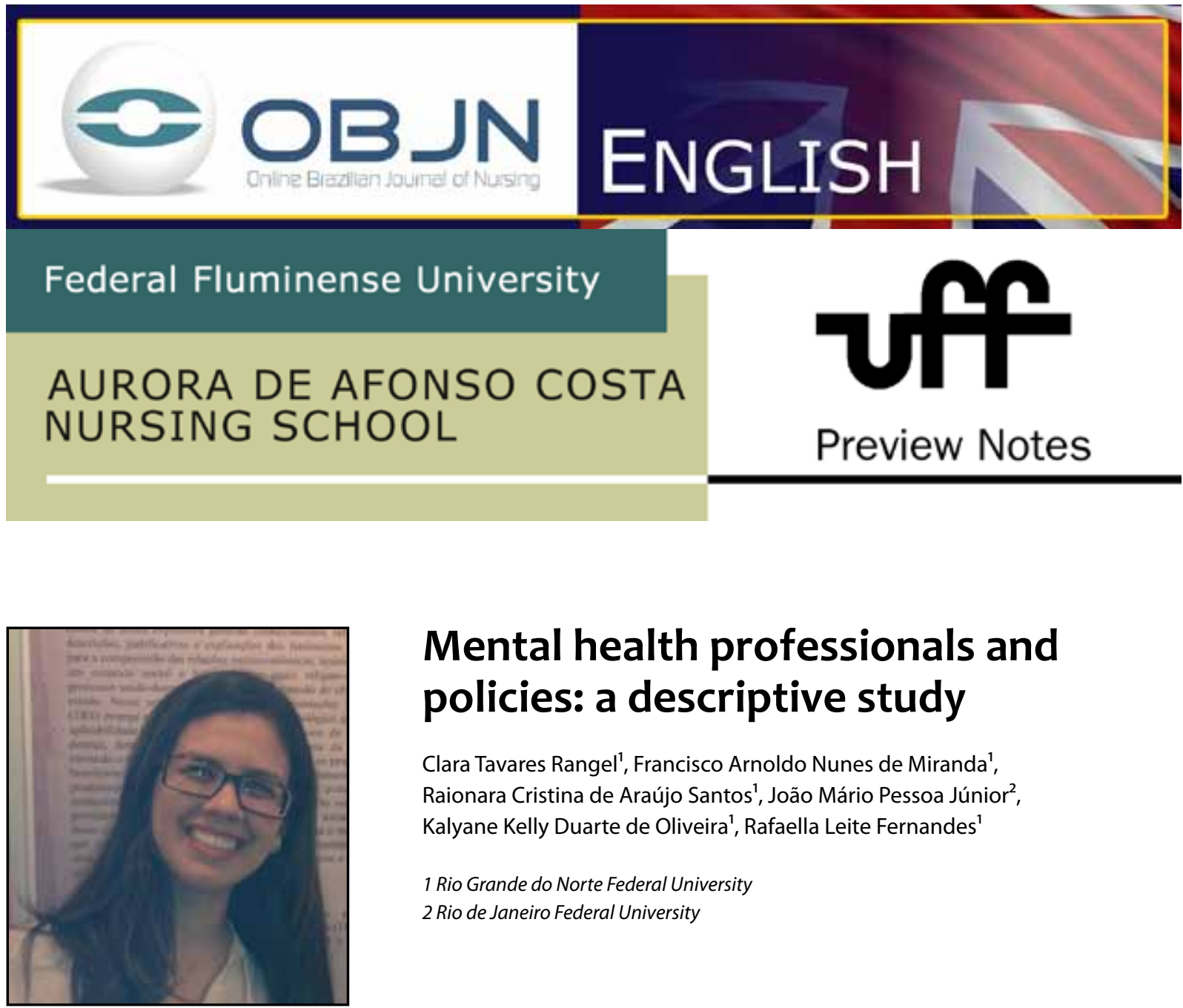

\title{
Mental health professionals and policies: a descriptive study
}

\author{
Clara Tavares Rangel', Francisco Arnoldo Nunes de Miranda', \\ Raionara Cristina de Araújo Santos ${ }^{1}$, João Mário Pessoa Júnior², \\ Kalyane Kelly Duarte de Oliveira', Rafaella Leite Fernandes ${ }^{1}$ \\ 1 Rio Grande do Norte Federal University \\ 2 Rio de Janeiro Federal University
}

\section{ABSTRACT}

The Brazilian psychiatric reform proposes substitutive treatment in order to favor de-institutionalized practices. Based on that, it is important to know the practical spectrum of this new policy, as well as the opinions of the professionals involved. Aim: To analyze the policies of mental healthcare followed by the professionals who work in the psychosocial care network of the Brazilian state of Rio Grande do Norte (RN, in Portuguese). Method: This is a descriptive study, with a quantitative-qualitative approach, involving data obtained from questionnaires and interviews used in conjunction with professionals and coordinators of the public mental healthcare services in the Brazilian state of RN, respectively. The quantitative results will be analyzed with the support of SPSS software in terms of descriptive statistics; the qualitative data will be analyzed using ALCESTE software and other systems. It is expected that the results generated by these methods can contribute to professional practices and to the workings of the mental healthcare services in terms of the description of each, and the observation of possible issues in the process.

Descriptors: Health Personnel; Mental Health Services; Mental Health. 


\section{INTRODUCTION}

The standards established by the Sanitary and Psychiatric Italian Democratic Reform were the yardsticks for the Brazilian Psychiatric Reform (RPB, in Portuguese) from the standpoint of the principles of de-institutionalization that both propose $^{(1)}$. In this context, it is possible to explore a restructuring of all health services, specifically the ones related to mental health, as such a restructuring requires new operational, theoretical, and methodological approximations. These will enable the insertion of the new mental health approach into the Strategies of Family Health programs (ESF, in Portuguese), with the aim of fulfilling the principles and directives of the Brazilian Unified Health System (SUS, in Portuguese).

Based on this new dynamic, the aim is to reduce the hospitalization in psychiatric centers of patients with mental disorders, and to search for other substitutive services. Among those new options, there are the Centers for Psychosocial Care (CAPS, in Portuguese).

However, it is recognized that the health system aims to incorporate technology, to diagnose and to treat mental disorders. To change such parameters, there is a need to reshape those professional projects related to the work of health professionals, aiming to present adaptive and adequate formats, incorporating interpersonal processes and a communicative approach. These processes will provide the the patient with greater accuracy and understanding of his health issue. Re-socialization will be achieved by the use of therapeutic techniques, involving the patient and his family ${ }^{(2-3)}$.

The present paradigm provides both professionals and healthcare service providers with the RPB proposals and, at the same time, some ideas rooted on the logic of mental institutions, thus impeding the full effectiveness of the theory and practices suggested by the reform ${ }^{(2)}$.

\section{GUIDING QUESTIONS}

What are the current policies of mental healthcare assistance that exist in the Brazilian state of Rio Grande do Norte? Which are the roles and tasks performed by the health team professionals in the public mental healthcare service provision of Rio Grande do Norte?

\section{AIMS}

To analyze mental healthcare policies, and the roles and tasks performed by the professionals who work in the psychosocial health network of Rio Grande do Norte.

\section{METHODS}

This is a descriptive piece of research, which adopts a qualitative-quantitative approach. It is currently in progress, performed in the 37 CAPS and two accredited psychiatric hospitals of the Brazilian state of Rio Grande do Norte. These are distributed over the eight Health Regions as follows: $1^{\text {st }}$ Region - São José de Mipibu, $2^{\text {nd }}$ Region - Mossoró, $3^{\text {rd }}$ Region - João Câmara, $4^{\text {th }}$ Region - Caicó, $5^{\text {th }}$ Region - Santa Cruz, $6^{\text {th }}$ Region - Pau dos Ferros, $7^{\text {th }}$ Region - Great Natal, and $8^{\text {th }}$ Region - Assú. For the data collection, this study used two instruments: an interview with the mental health coordinators of the 27 municipalities and of the state, and a questionnaire involving professionals with a college-level education (physicians, nurses, psychologists, social workers, etc.) and with technical-level professionals who work in the previously-mentioned 
psychosocial healthcare services. In total there are 564 subjects - 264 college-level professionals and 200 technical-level professionals, such as nursing technicians.

The interviews with the mental health coordinators are semi-structured, with four open questions. These deal with the mental health policies and the services provided by the municipality the interviewees work in; the questionnaire also has open and closed questions about the socioeconomic profile of the participants and their roles, together with their opinions about mental health services and policies.

The criteria for inclusion were being employed by the researched mental health service provider for at least six months, and working for at least 20 hours per week. The professionals who had been recently employed by the researched service provider, or who were on vacation, medical or any other leave period, or even under any other situation that impeded these professionals from being on duty during the period of data collection, were excluded.

The quantitative results will be analyzed under the Statistical Package for Social Science (SPSS) software, through descriptive statistics, by constructing charts and tables. The qualitative data will be considered through the use of ALCESTE software, and a system of categorization, and discussed in terms of the scientific literature.

This study was approved by the Commission of Ethics in Research, of Rio Grande do Norte Federal University (UFRN, in Portuguese), under protocol 217.808, in March $1^{\text {st }} 2013$.

\section{REFERENCES}

1. Santos RCA, Pessoa Junior JM, Fernandes RL, Carvalho SR, Miranda FAN. Reflections on the Brazilian Psychiatric Reform and its dimensions. Rev eferm UFPE on line [internet]. 2013 [cited 2014 Sept 25]; 7(esp):6705-13. Available from: http:// www.revista.ufpe.br/revistaenfermagem/index. php/revista/article/view/4770/pdf_405

2. Barros S, Salles M. Mental health care management in the Brazilian National Health System. Rev Esc Enferm USP. 2011;45(2):1780-1785.

3. Pessoa Júnior JM, Miranda FAN. The trajectory of dr. Elger Nunes' day-hospital: a historical view of psychiatry and mental health in Rio Grande do Norte. Online braz j nurs [internet]. 2012 Oct [cited 2014 Sept 25]; 11 Suppl 1:559-62. Available from: http://www.objnursing.uff.br/index.php/ nursing/article/view/3760

All the authors have participated in the stages of this paper, according to the recommendations of the International Committee of Medical Journal Editors (ICMJE, 2013): (a) substantial participation under the conceptualization or conception of the manuscript, or of the collection, analysis, or interpretation of data; (b) the elaboration of the body work, or the critical review of intellectual propriety; (c) the approval of the submitted version. All authors declare, for all due purpose, that they are responsible to the content related to all aspects of the article sent to OBJN. They also guarantee that the questions related to the precision or the integrity of each and any part of this article was properly investigated and solved. They, therefore, exempt OBJN from any solidary participation of eventual imbroglios regarding the matter here described. All authors declare any conflict of interests, either economical or of relationships, which may have influenced the writing and/or the interpretation of the findings. This declaration was digitally signed by all authors, according to the directives described by the ICMJE, which model is available from http://www.objnursing.uff. br/normas/DUDE_final_13-06-2013.pdf

Received: $10 / 01 / 2014$

Revised: 10/23/2014

Approved: $10 / 23 / 2014$ 